
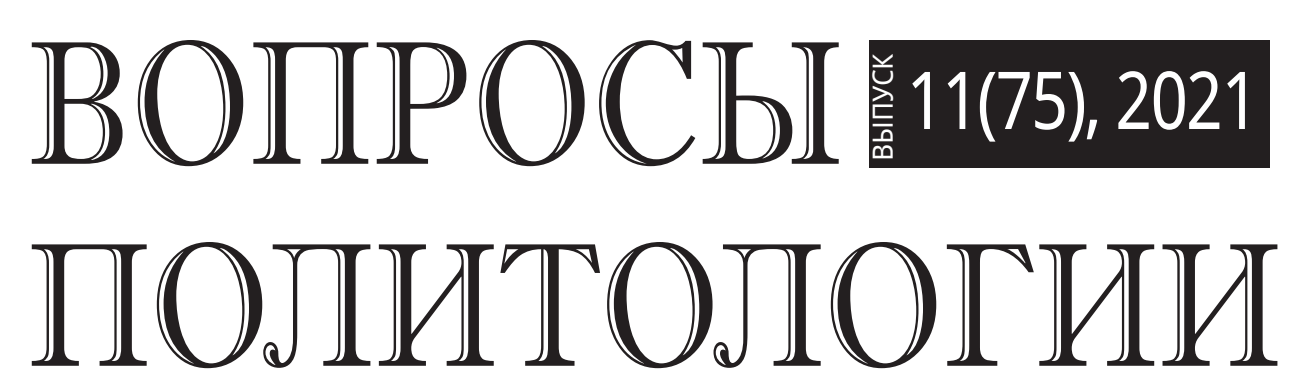

Научный журнал

Журнал «Вопросы политологии» включен

в Перечень рецензируемых научных изданий

ВАК при Министерстве науки и высшего образования РФ

по политическим наукам, в которых должны быть опубликованы основные научные результаты на соискание ученой степени кандидата наук, на соискание ученой степени доктора наук

Журнал включен в Перечень научных изданий рекомендованных ВАК Республики Узбекистан для публикации основных научных результатов диссертаций по политическим и философским наукам 
Председатель Редакционного Совета - ПЛАТОНОВ В.М.,

к.ю.н., заведующий кафедрой политического анализа и управления РУДН,

Председатель Московской городской Думы (1994-2014 гг.)

\section{Редакционный Совет}

АВАЗОВ

Камиль Халлиевич

\section{АСТВАЦАТУРОВА}

Майя Арташесовна

БЛОХИН

Владимир Владимирович

БОЖАНОВ

ВАНКОВСКА

Биляна

\section{ВЕДРИН}

Оливье

Наталия Михайловна

ГОНЧАРОВ

Пётр Константинович

ГРАЧЁВ

Михаил Николаевич

ДЭМБЭРЭЛ К.

ДОНАЙ

Лукаш

ЖИЛЬЦОВ

Сергей Сергеевич

КАРАДЖЕ

Татьяна Васильевна

КАССАЕ НЫГУСИЕ

В. МИКАЭЛЬ

КОВАЛЕНКО

Валерий Иванович

КОМЛЕВА

Валентина Вячеславовна

КРИВОКАПИЧ

Борис

МЕДВЕДЕВ

Николай Павлович

МИХАЙЛОВ

Вячеслав Александрович

НАЗАРОВА

Елена Александровна

НАЗАРОВ

Александр Данилович

НАСИМОВА

Гульнара Орленбаевна

НИСНЕВИЧ

Юлий Анатольевич

ОРЛОВ

Игорь Борисович

ПАХРУТДИНОВ

Шукритдин Ильясович

ПЛЯЙС

Яков Андреевич

ПРЯХИН

Владимир Федорович

ПУСЬКО

Виталий Станиславович

СЛИЗОВСКИЙ

Дмитрий Егорович

СЫЗДЫКОВА

Жибек Сапарбековна

ХОПЁРСКАЯ

Лариса Львовна

ШАРКОВ

Феликс Изосимович

ЯН ФУЛИНЬ
Владимир Александрович

ВЕЛИКАЯ

д.ф. (PhD) по полит. наукам, Региональный центр переподготовки и повышения квалификации работников народного образования Сурхандарьинской области (Узбекистан, г. Ташкент) д.П.н., профессор, Пятигорский государственный университет (Россия, г. Пятигорск) д.и.н., профессор, РУДН (Россия, г. Москва)

д.и.н., профессор, Белорусский Национальный технический университет (Белоруссия, г. Минск)

профессор политологии и международных отношений

факультета философии Университета Святых Кирилла и Мефодия

(Македония, г. Скопье)

профессор, ректор «Континентального университета в Киеве»

(Франция, г. Париж)

д.п.н., профессор, ИСПИ ФНИСЦ РАН, РГГУ (Россия, г. Москва)

д.с.н., профессор, Российский университет транспорта (МИИТ)

(Россия, г. Москва)

д.П.н., профессор, РГГУ (Россия, г. Москва)

доктор (PhD), Институт международных отношений АН Монголии (Монголия, г. Улан-Батор)

д.п.н., профессор, Университет им. Адама Мицкевича в Познани (Польша, г. Познань)

д.П.н., профессор, Дипломатическая академия МИД РФ

(Россия, г. Москва)

д.ф.н., профессор, МПГУ (Россия, г. Москва)

д.и.н., профессор, РУДН (Россия, г. Москва)

д.ф.н., профессор, МГУ им. М.В. Ломоносова (Россия, г. Москва)

д.с.н., профессор, РАНХиГС при Президенте РФ (Россия, г. Москва)

д.ю.н., Унион-Никола Тесла университет (Сербия, г. Белград)

д.п.н., профессор, главный редактор журнала (Россия, г. Москва)

д.и.н., профессор, РАНХиГС при Президенте РФ (Россия, г. Москва)

д.с.н., профессор, МГИМО МИД России (Россия, г. Москва)

д.и.н., профессор, МАИ (Россия, г. Москва)

д.п.н., профессор, Казахский Национальный университет

им. Аль-Фараби (Казахстан, г. Алматы)

д.п.н., профессор, НИУ «Высшая школа экономики»

(Россия, г. Москва)

д.и.н., профессор, НИУ «Высшая школа экономики»

(Россия, г. Москва)

д.п.н., профессор, Институт переподготовки и повышения

квалификации руководителей и специалистов системы народного

образования имени А. Авлони (Узбекистан, г. Ташкент)

д.и.н., Д.П.н., профессор, Финансовый университет при Правительстве РФ (Россия, г. Москва)

д.п.н., профессор, РГГУ (Россия, г. Москва)

д.ф.н., профессор, ВА РВСН им. Петра Великого (Россия, г. Москва)

д.и.н., профессор, РУДН (Россия, г. Москва)

д.и.н., профессор, ИСАА МГУ им. М.В. Ломоносова

(Россия, г. Москва)

д.П.н., профессор, Киргизско-Российский славянский университет

(Киргизия, г. Бишкек)

д.с.Н., профессор, РАНХиГС при Президенте РФ (Россия, г. Москва)

проректор Хэйлунцзянского института иностранных языков (КНР, г. Харбин)

\section{Редакционная коллегия}

Главный редактор - МЕДВЕДЕВ Н.П., д.П.Н., профессор

Абрамова О.Д. (д.П.н.)

Насимова Г.О. (д.п.н.)

Кетцян Г.В. (к.П.н. - зам. гл. редактора)
Шкурина С.С. (к.П.н. - ответ. редактор)

\section{ЖУРНАЛ ВКЛЮЧЕН В ПЕРЕЧЕНЬ ВАК РФ}

\author{
УЧРЕЖДЕН \\ ООО «Издательство \\ «Наука сегодня»
}

Журнал зарегистрирован

Федеральной службой

по надзору в сфере массовых коммуникаций, связи и охраны культурного наследия

Рег. № ПИ № ФС77-46176 от 12 августа 2011 г.

Журнал издается ежемесячно

Журнал включен в базу РИНЦ

(Российский индекс

научного цитирования)

Включен в каталог

Ulrich's Periodicals Directory

Пятилетний импакт-фактор: 1,489.

Адрес редакции:

115598 , г. Москва, ул. Загорьевская, д. 10, корп. 4, цокольный этаж, помещение I, комната 7-1, офис 4

Тел.: (910) 463-53-42

Интернет-ресурс:

www.voprospolitolog.ru

E-mail: voprospolitolog@yandex.ru

Мнение авторов может не совпадать с мнением редакции.

При перепечатке ссылка

на журнал обязательна.

Научные статьи, публикуемые в журнале подлежат обязательному рецензированию.

Ответственный редактор Шкурина С.C.

Перевод

Чернышова Е.B.

Компьютерная верстка Анциферова А.С.

Подписано в печать 25.11.2021

Формат 60×84/8. Объем 24,3 Печать офсетная Тираж - 1000 эКз.

(1-й завод - 500 экз.) Заказ № 000.

Отпечатано в типографии OOO «Белый ветер»

115054, г. Москва, ул. Щипок, 28 Тел.: (495) 651-84-56 
ISSN 2225-8922 (print)

12 выпусков в год и

4 выпуска в год переводной (англ.) версии

Языки: русский, английский

http://voprospolitolog

Входит в перечень рецензируемых научных изданий ВАК РФ Включен в каталог периодических изданий Ульрих

(Ulrich's Periodicals Directory: http://www.ulrichsweb.com)

Материалы журнала размещаются на платформе РИНЦ

Российской научной электронной библиотеки, Electronic Journals Library Cyberleninka

Подписной индекс издания в каталоге агентства Роспечать 70035

\section{Цели и тематика}

Журнал ВОПРОСЫ ПОЛИТОЛОГИИ - периодическое международное рецензируемое научное издание в области политических исследований. Журнал является международным как по составу редакционного совета и редколлегии, так и по авторам и тематике публикаций.

Научный журнал издается с 2011 года в издательстве «Наука сегодня». С 2016 года издается переводная (англ.) версия журнала. С момента своего создания, журнал ориентировался на высокие научные и этические стандарта и сегодня является одним из ведущих политологических журналов России.

Цель журнала - способствовать научному обмену и сотрудничеству между российскими и зарубежными политологами.

Журнал предназначен для публикации результатов фундаментальных и прикладных научных исследований. Тематическая направленность журнала отражается в следующих постоянных рубриках: «История и философия политики», «Политические институты, процессы и технологии», «Политическая регионалистика и этнополитика», «Политическая культура и идеологии», «Политические проблемы международных отношений и глобализации».

Формат публикаций: научные статьи, обзорные научные материалы, материалы круглых столов, научные рецензии, научные сообщения, посвященные исследовательским проблемам в сфере политики и политологии.

В своей деятельности редакционный совет и редколлегия журнала руководствуется принципами, определяемыми ВАК России для научных журналов, в том числе: наличие института рецензирования для экспертной оценки качества научных статей; информационная открытость издания; наличие и соблюдение правил и этических стандартов представления рукописей авторами.

Целевой аудиторией журнала являются российские и зарубежные специалисты-политологи, а также аспиранты и магистры, обучающиеся по направлениям политология, государственное и муниципальное управление и международные отношения.

Журнал строго придерживается международных стандартов публикационной этики, обозначенных в документе СОРЕ (Committee on Publication Ethics) http://publicationethics.org

Полные сведения о журнале и его редакционной политике, требования о подготовке и публикации статей, архив (выпуски c 2011 года) и дополнительная информация размещена на сайте: http://voprospolitolog.ru

Электронный адрес: voprospolitolog@yandex.ru

ISSN 2225-8922 (print)

12 issues a year plus 4 issues a year of the translated (eng.) version Languages: Russian and English http://voprospolitolog

Included in the list of peer-reviewed scientific publications of the Higher Attestation Commission of the Russian Federation Included in the Ulrich's Periodicals Directory Materials of the journal are placed on the RSCI platform of the Russian scientific electronic library - Electronic Journals Library Cyberleninka Subscription index of the journal in the Rospechat Agency catalogue is: 70035

\section{Objectives and themes}

Academic journal "Political Science Issues" is an international peer-reviewed scientific periodical in the field of political studies. The journal has an international character because of the composition of its Editorial Board, its editors, its contributing authors and topics of its publications.

The scientific journal is published since 2011 at the "Publishing House "Science Today". Translated (eng.) version of the journal is published since 2016. Since its inception, the journal was guided by high scientific and ethical standards and today it is one of the leading political science journals in Russia.

The purpose of the journal is to promote scientific exchange and cooperation between Russian and foreign political scientists.

The journal is intended for the publication of the results of fundamental and applied scientific research. Thematic focus of the journal is reflected in the following permanent headings: "History and philosophy of politics," "Political institutions, processes and technologies," "Political regionalism and ethno-politics," "Political culture and ideologies," "Political problems of international relations and globalization."

Format of publications: scientific articles, reviews, scientific materials, materials of round tables, scientific reviews, scientific reports devoted to research problems in the field of politics and political science.

The Editorial Board and the editors of the journal in their activities are guided by the principles defined by VAK of Russia for scientific journals, including: presence of the institute of peer review for the expert quality assessment of scientific articles; information openness of the publications; availability and compliance with the rules and ethical standards for the submission of manuscripts by the authors.

The target audience of the journal is Russian and foreign specialists-political scientists, as well as graduate students and masters in the fields of political science, state and municipal management and international relations.

The journal strictly adheres to the international publishing standards and publication ethics identified in the COPE (Committee on Publication Ethics) document. http://publicationethics.org.

Full details of the journal and its editorial policy, requirements to the preparation and publication of articles, archive (issues since 2011) and additional information are available on the website: http://voprospolitolog.ru

E-mail address: voprospolitolog@yandex.ru 


\section{ИСТОРИЯ И ТЕОРИЯ ПОЛИТИКИ}

Гончаров П.К. Современная политическая культура:

к определению понятия 3008

Солодова Г.С. Поиск универсальных закономерностей критический взгляд Р. Будона на теории социальных изменений. 3014

Берёзкина E. Ю. Вариации интерпретации популизма

в современной политологии..... 3020

\section{ПОЛИТИЧЕСКАЯ ИСТОРИЯ РОССИИ}

Гаджиев М.M. Драматическая эволюция государственно-конфессиональных отношений в Республике Дагестан в постсоветский период: от религиозно-политической конфронтации до региональной стабилизации 3028

Наледин И.И. Политические партии

Крымского полуострова и их влияние на избирательную систему Крыма в постсоветский период

\section{ПОЛИТИЧЕСКАЯ СОЦИОЛОГИЯ}

Абрамова М.А. Применение социокультурного

и интеракционисткого подходов в изучении трансформаций социокультурного пространства

Макаренко К.М., Панкратов С.А., Панкратова Л.С.

Трансформация гражданского протеста в современной России:

выбор форм онлайн и офлайн активности.

Цуприк М.И. К вопросу об исследовании

инструментария изучения политической идентичности.

\section{ПОЛИТИЧЕСКИЕ ИНСТИТУТЫ, ПРОЦЕССЫ И ТЕХНОЛОГИИ}

Володина Н.А., Ретинская В.Н. Особенности реализации российской государственной антикоррупционной политики в условиях информационного общества и электронного государства.

Андреева Ю.В., Липатова A.B. Факторы влияния политических традиций на технологии конструирования медиаобраза регионального лидера.

Калиев И.А., Алтыбасарова М.А. Информационные технологии в политическом процессе: политологический анализ ....

Прончев Г.Б., Михайлов А.П. Виртуальные социальные среды интернета как инструмент политической борьбы

Алексеев Р.А., Еж⿻в Д.А., Шакурова Н.Е. Практика организации электронных референдумов в России: особенности апробации .

Добрынина М.В., Огородов Д.А. Формирование советской политики в области физкультуры, спорта и спортивного образования: идеологические основания 
Мадюкова $\boldsymbol{C}$. . Н. Национальная политика

в социокультурном пространстве региона

(на примере Республики Алтай).

Николенко $\boldsymbol{A}$. $A$. Легитимация властных структур и ее особенности

в рамках концепции «русской локальной цивилизации»

Ocunoв A.B. Социально-политический мониторинг

и социально-медийная предиктивная аналитика как инструменты

и технологии консолидации политической власти

Сабирова H.C. Влияние средств массовой информации

на политическую культуру современной России

Лапшина Д.М., Попов С.И. Кадровая политика государственной

гражданской службы России на современном этапе

и пути ее совершенствования

Калиниченко A.O. Российский федерализм

в развилке конституционной реформы

Файзиев 3. Влияние религиозной толерантности

на межнациональные отношения

Лебедева $\boldsymbol{E}$. $\boldsymbol{A}$. Снижение проходного барьера

и наличие графы «против всех» как показатели

демократичности выборов в современной России

Малахов А.А. Концепция всеобщего благосостояния

и ее реализация в целях и функциях государства

Романова Ю.А. Развитие научно-технической

инновационной инфраструктуры субъектов Российской Федерации,

входящих в состав ЦФО

Салимов Д.М. Политическая цензура

и сетевые СМИ в современном Таджикистане

\section{ГОСУДАРСТВЕННОЕ УПРАВЛЕНИЕ И ОТРАСЛЕВЫЕ ПОЛИТИКИ}

Жолманов А.С., Афонин М.В., Кривова А.Л. Коррупционные риски

как категория антикоррупционной политики.

ТЕОРИЯ И ИСТОРИЯ МЕЖДУНАРОДНЫХ ОТНОШЕНИЙ И ВНЕШНЕЙ ПОЛИТИКИ

Абрамов В.Л., Прокофьев В.А. Устойчивые конкурентные

преимущества стран в контексте эволюции теоретических подходов

по развитию мировой торговли

Юрасов И.А., Володина Н.А. Историческая память

российской молодежи как основа формирования

государственно-ориентированной личности

Тушков А.А., Животова Д.А. Вестернизация Японии

как импрувер культурного кроссинговера 
Чемшит А.А., Ковалевский А.А. Глобальные

и европейские противоречия в современном

геополитическом дискурсе в Болгарии (Часть II)

Воронина H.A. Механизмы транснациональной коммуникации

в сфере миграции в современную эпоху.....

Агоннуде Бидолей Вианней Фредди. Приоритеты ЮАР в G20 .

Хабаров И.А. Маршруты символического

конструирования пространства:

от составления карты к штурму горизонтов

Чучин М.И., Адутов Р.P. Система поддержки принятия

решений в деятельности различных организаций

Иванченко М.A. Развитие политической системы

Аргентины в 30-40 годы ХХ века

Баракат Kaйс A.M. Внешняя политика США по отношению

к арабо-израильскому конфликту на современном этапе.

Казарян С.A., Бозоян T.P. Корпоративная социальная деятельность

транснациональных корпораций Соединенных Штатов Америки

в странах Юго-Восточной Азии

Власов A.B. Современные технологии публичной дипломатии

$\boldsymbol{E} \boldsymbol{\varepsilon}$

для контроля за деятельностью мировых ТНК

Золотарев H.A. Зарубежный опыт интеграции мигрантов:

практика современной Германии.

Клюкин Н.Д. Цифровая дипломатия в эпоху больших данных

Лебедева Е.И., Присекин А.А. Современное политическое

лидерство в Европе в контексте религиозного ренессанса

Петросян Ф.A. Политическая активность в шведском Риксдаге

сторонников и противников присоединения к НАТО

Симонова А.И. Анализ государственной политики Китая в области молодежных браков

Фаздалова Р. Политическая значимость Казани

в развитии китайско-российских отношений

Дуань Жань. Взаимодействие КНР со странами Центральной Азии

в области безопасности в рамках ШОС

Нина Рамос Росио Леонор. Внешнеполитический

вектор Бразилии в условиях становления нового мирового порядка

Добромыслов А.С. Политические аспекты глобального старения

\section{СТУДЕНЧЕСКАЯ НАУКА}

Лю Лу. США и Россия на пороге новой холодной войны. 
магистрант

Белорусского государственного университета, Республика Беларусь, г. Минск

\section{США И РОССИЯ НА ПОРОГЕ НОВОЙ ХОЛОДНОЙ ВОЙНЫ}

Сколько бы раз ни говорилось о том, что отнотения между Россией и западными странами уже не могут ухудшиться, новостная повестка дня доказывает нам обратное. Так министр обороны Германии пригрозила России применением ядерного оружия, если та не подчинтся директивам НАТО. Хотя сама Германия не обладает ядерным оружием, подразумевалось, что атака может быть предпринята американским арсеналом с европейской территории. И такая риторика становится все более частой. Тема холодной войны России и США, как двух крупнейших держав обсуждается в разных странах с завидной периодичностью. Президент США Джо Байден заявил, что не стремится к новой холодной войне. Однако, большинство европейцев считают, что она уже идет между США и их главными соперниками - Китаем и Россией. Некоторые европейцы также считают свою страну непосредственным участником конфликта. В рамках данной статьи мы проанализируем различные точки зрения по данному вопросу. А так же сделаем ряд выводов.

Ключевые слова: Россия, США, холодная война, противоречия, противостояние.

В исследовании Европейского совета по международным отношениям было сделано открытие после проведения опроса в 12 странах-членах ЕС. По данным опроса, $62 \%$ респондентов считают, что между США и Китаем идет новая холодная война, а 59\% видят, что тоже самое происходит между США и Россией. Около $15 \%$ европейцев считают, что их страна находится в состоянии новой холодной войны с Китаем, и $25 \%$ - с Россией [2].

Около $31 \%$ европейцев считают, что ЕС сейчас находится в состоянии конфликта с Китаем, в то время как $35 \%$ ответили, что это не так. Около $44 \%$ опрошенных считают, что ЕС находится в состоянии новой холодной войны с Россией. Данные опроса свидетельствуют о том, что существует явная опасность увеличения пропасти между европейским общественным мнением и мнением в США. 
Как свидетельствуют результаты данных социологических исследований, проблема напряженных двухсторонних и международных отношений между США, Россией и Китаем становится одной из актуальных в современной политической науке.

Следует подчеркнуть, что в работах российских и зарубежных авторов, опубликованных в последние годы, освещается широкий спектр вопросов близких к данной предметной области $[1 ; 3 ; 5 ; 6 ; 7 ; 10 ; 12 ; 13 ; 14]$.

Однако проблему «новой холодной войны» между тремя ядерными державами нельзя назвать однозначно исчерпанной. В силу многих объективных обстоятельств изучение обозначенной темы продолжает сохранять высокий уровень актуальности.

Сколько бы раз ни говорилось о том, что отношения между Россией и западными странами уже не могут ухудшиться, новостная повестка дня вновь и вновь доказывает нам обратное. В частности, министр обороны Германии Аннегрет Крамп-Карренбауэр дала интервью [4], в котором пригрозила России применением ядерного оружия, если та не подчинится директивам НАТО. Хотя Германия сама не обладает ядерным оружием, подразумевалось, что американский арсенал может быть применен с европейской территории.

Министр обороны России Сергей Шойгу прокомментировал мечты своего немецкого коллеги о новой войне, сказав, в частности, что «мы должны помнить, чем заканчивается стягивание сил к границам России». Вполне справедливое замечание в адрес страны, развязавшей две мировые войны. Директор Службы внешней разведки России Сергей Нарышкин также рассказал об агрессивных военных планах западных партнеров и указал на тщетность попыток захвата российской территории.

До этого Россия решила приостановить работу своего постоянного представительства при НАТО с 1 ноября 2021 года в ответ на решение о лишении аккредитации восьми членов миссии. Закрытие дипломатических представительств само по себе является тревожным сигналом с точки зрения военной безопасности, но это лишь верхушка айсберга.

В этом плане можно отметить, что российские политики проявляют большую активность в обсуждении перспектив военных конфликтов с Западом, что говорит о том, что этот вопрос уже активно обсуждается российскими элитами, и они серьезно подходят к риску военных конфликтов у своих границ. И в этой связи стоит вспомнить недавнюю статью бывшего президента России и ныне заместителя председателя Совета безопасности Дмитрия Медведева об украинской ситуации. А вот в этой статье он заявляет о том, что нынешнее правительство Украины абсолютно несерьезно к переговорам и не видит никаких перспектив мирного сосуществования ни со своими украинскими политическими элитами, ни с ее европейскими кураторами.

Кроме того, министр обороны США Ллойд Остин заявил, что гарантии военной помощи Киеву в случае агрессии со стороны России и британский 
проект военно-материальных поставок в виде поставок ракет Brimstone или совместного строительства военных кораблей [8]. Эти политические жесты показывают, что англо-саксонские элиты точно так же настроены к эскалации конфликта с Россией, и точкой приложения сил они выбрали территорию Украины.

Как представляется, именно в Восточной Европе ситуация выглядит наиболее благоприятной для того чтобы начать эскалацию военной ситуации в восточной ее части. Уровень вакцинации в России вновь бьет рекорды по заболеваемости и смерти, в России вводят режим изоляции, что означает дополнительный ущерб бизнесу и благосостоянию граждан. Европу нельзя назвать лучшей страной в сравнении с Россией по причине развития энергетического кризиса и проблем с поставками газа, с риском холодов. При этом на экономику стран ЕС также ложится тяжелый груз в виде расходов на создание «зеленой» экономики, и не все с ним могут справиться.

C Запада на Россию через Украину давление очень удобное, поскольку на своих южных границах, где она уже не может быть изолирована от процессов дестабилизации, Турция уже вынуждена отвлекаться на процессы дестабилизации, которые вызваны Турцией в рамках ее политики экспансия в Евразии. Однако, если рассматривать ситуацию с падением старого режима в Афганистане и приход к власти правительства талибов, который тоже не является проблемой одной конкретной страны, однако представляет собой мощный знак для всех жителей Центральной Азии, страдающей от низкого уровня жизни, невежества или несостоятельных и коррумпированных местной элиты. А в районе границы России возникают очаги напряженности. Для чего они были созданы, и кто их планировал, если это была стратегия кого-то из участников?

В этом плане стоит упомянуть еще один важный момент внутренней политики России - это отношение к ним. Более того в стране проживают большое количество нелегальных мигрантов из Таджикистана, Узбекистана или Кыргызстана, которые почти полностью заняты в сфере неквалифицированного труда - это сфера ЖКХ [9]. В крупных городах они совершают большую часть преступлений, совершая их регулярно, а также воруя и насилуя. Во время первой блокировки Москвы в 2020-м году, когда большинство мигрантов из Средней Азии вернулись домой, количество преступлений, совершенных в столице снизились на $75 \%$. Однако несмотря на такую очевидную угрозу для своих граждан и правительства, власти недавно амнистировали 300000 мигрантов, ранее депортированых за преступления, не в силах иным образом восполнить дефицит дешевой рабочей силы. При ухудшении внутренней обстановки и при наличии других факторов, влияющих на криминогенную обстановку (война, экономический кризис, экологическая катастрофа), мигранты могут стать еще одним дестабилизирующим фактором, существенно ухудшающим криминогенную ситуацию [11]. 
При этом предстоящая зима будет серьезным испытанием для инициатив мирного сотрудничества ввиду описанных выше объективных обстоятельств, и наступление весеннего периода в северных широтам часто связано с повышением военной активности. Следующий масштабный акт украинской агрессии на Донбассе состоится в апреле этого года; за оставшейся до следующей весны срок инструкторы НАТО успеют обучить украинских военнослужащих в дополнение к американским и британским вооружениям. На данный момент вероятность возникновения нового конфликта достаточно высока, и его основной целью является именно отвлечение и ослабение России.

\section{БИБЛИОГРАФИЧЕСКИЙ СПИСОК:}

1. Вэй Юйжуй. Влияние пандемии на развитие отношений Китая и других мировых государств // Вопросы национальных и федеративных отношений. 2021. Т. 11. № 4 (73).

2. Грэм T. Китай - Россия - США: отношения и стратегические треугольники // Polis: Journal of Political Studies. 2020. № 6.

3. Капитонов А.А. Влияние итогов президентских выборов 2020 года в США на реализацию целей в области устойчивого развития в национальном и глобальном измерениях // Вопросы национальных и федеративных отношений. 2021. Т. 11. № 3 (72).

4. Манкоф д. США в мире соперничающих великих держав // Международная аналитика. 2020. Т. 11. № 3.

5. Моисеев А.В., Шангараев Р.Н. Межгосударственное сотрудничество по снижению рисков глобальных ядерных угроз: концепции и практика // Вопросы национальных и федеративных отношений. 2021. Т. 11. № 3 (72).

6. Пряхин В.Ф. Захлопнется ли ловушка Фукидида? О возможных и невозможных построениях геополитического четырехугольника «Россия Китай - США - Европейский Союз» // Евразийский Союз: вопросы международных отношений. 2020. Т. 9. № 2 (32).

7. Рубан Л.С., Печерища В.Ф., Бояркина А.В. Россия в новой геополитической и геоэкономической реальности между Вашингтоном и Пекином // Вопросы национальных и федеративных отношений. 2021. Т. 11. № 8 (77).

8. Син Ж. Позиция и оценка Китайской Республики на события 2014 года на Украине // 41.03.05. Международные отношения. 2021.

9. Тонких В.А., Кондратенко Л.И. Россия - США: от холодного мира к холодной войне. 2021.

10. Тушков А.А., Оселедец А.Г., Тушков А.А. Сценарии развития стратегии внешнеполитического курса Соединенных Штатов в Индо-Тихоокеанском регионе // Евразийский Союз: вопросы международных отношений. 2021. T. 10. № 5 (39). 
11. Фэн Ю. Мировой порядок в «постпандемическом мире» и стратегический выбор России // Сравнительная политика. 2021. Т. 12. № 3.

12. Чжан Лумэн. Изменения в мировом порядке в постэпидемическую эпоху и ролевое позиционирование Китая // Евразийский Союз: вопросы международных отношений. 2021. Т. 10. № 1 (35).

13. Явчуновская Р.А. Современное состояние политики обеспечения безопасности стран Содружества // Евразийский Союз: вопросы международных отношений. 2019. Т. 8. № 2 (28).

14. Medvedev N.P., Slizovsky D.E. Review of the Article by Pyzh V.V. and Frolov A.E. "Political Security of the State and Political Stability of Society as an Object of Political Analysis" // Political Science Issues. 2018. T. 8. № 1 (29).

\author{
$\boldsymbol{L I U} \boldsymbol{L} \boldsymbol{U}$ \\ Graduate student \\ Belarusian State University, \\ Minsk, Belarus
}

\title{
THE USA AND RUSSIA ARE ON THE BRINK OF A NEW COLD WAR
}

No matter how many times it has been said that relations between Russia and Western countries can no longer deteriorate, the news agenda proves us otherwise. For example, the German defence minister threatened Russia with the use of nuclear weapons if it does not comply with NATO directives. Although Germany itself does not possess nuclear weapons, it was implied that an attack could be launched by an American arsenal from European territory. And such rhetoric is becoming more and more frequent. The topic of the Cold War between Russia and the United States as the two major powers is discussed in various countries with an enviable frequency. US President Joe Biden has stated that he is not seeking a new Cold War. However, most Europeans believe it is already underway between the US and its main rivals, China and Russia. Some Europeans also see their country as a direct participant in the conflict. In this article we will analyse the various viewpoints on this issue. We will also draw some conclusions.

Key words: Russia, US, Cold War, contradictions, confrontation. 